\title{
Research on the Deep Interaction of Online Teaching and Its Value Embodiment
}

\author{
Peigang Liu, Yuting Zhang, Junjie Zhao \\ School of Business Administration, Anhui University of Finance \& Economics, Bengbu, China \\ Email:2078088451@qq.com
}

How to cite this paper: Liu, P.G., Zhang, Y.T. and Zhao, J.J. (2021) Research on the Deep Interaction of Online Teaching and Its Value Embodiment. Open Access Library Journal, 8: e7517.

https://doi.org/10.4236/oalib.1107517

Received: May 12, 2021

Accepted: June 27, 2021

Published: June 30, 2021

Copyright $\odot 2021$ by author(s) and Open Access Library Inc.

This work is licensed under the Creative Commons Attribution International License (CC BY 4.0).

http://creativecommons.org/licenses/by/4.0/

(c) (i) Open Access

\begin{abstract}
The purpose of this study is to promote deep interaction in online teaching to be paid more attention to, and to provide guidance and suggestions for the implementation of deep interaction in online teaching. Make online teaching interaction break through the limitation of traditional teaching interaction, attach importance to the innovation of the content and form of teaching interaction, and further form the depth of online teaching interaction; In order to adapt to the interactive characteristics of college students in the new era and promote the comprehensive development of students' information quality, a new type of teacher-student relationship can be constructed to trigger students' deep learning. In collection, on the basis of analysis of a large number of research data, analysis of the connotation of the traditional teaching of interaction, think the connotation of the traditional teaching interaction can't cover online interactive teaching content and form, and online interactive teaching is more form diversification, depth of content, the interaction process of digitalization, digital interactive features such as interactive evaluation, Therefore, the connotation of the deep interaction of online teaching is expanded. On the classification of the interactive teaching, previous studies mainly in view of the interaction of traditional classroom teaching, cannot reflect the type of online interactive teaching, this study based on the online interactive teaching depth delay sexual characteristics, the types of online interactive teaching, online interactive teaching depth can be divided into interpersonal interactions, and interpersonal interactive time delay, the known interaction and people skills four types; Finally, this study discusses the value of deep interaction of online teaching in teacher-student relationship, deep learning, adapting to the personality characteristics of modern students, and training students' comprehensive development of information quality.
\end{abstract}

\section{Subject Areas}

Higher Teaching Theory, Teaching Method 


\section{Keywords}

Online Teaching, Deep Interaction of Teaching,

Online Interactive Classroom, Interpersonal Delayed Interaction

\section{Introduction}

Influenced by the epidemic, since March 2020, universities across the country have successively carried out the practice of online teaching mode. Through various online teaching activities, both teachers and students have gradually gained a deeper and more comprehensive understanding and application of online teaching. However, what is the difference between online teaching interaction and traditional classroom interaction, and what is the value of it?

Teaching is an activity of communication and cooperation, while classroom is a platform for interaction, cooperation and exploration. Classroom and online classroom are the main forms of teaching at present, and teaching is not only classroom teaching, but also includes the teaching outside the classroom. Teaching process is an interactive process among teachers, students and media (including textbooks, information technology, media, etc.). With the progress of teaching activities, a series of teaching interactions are produced. Teaching interaction is the most active factor in teaching activities, which has a significant impact on teaching quality and effect.

\subsection{Research Background}

The main difference between online teaching and traditional teaching is the change of classroom form and teaching environment. Traditional classroom has the innate advantage of teaching interaction. It has been a habit formed by people for a long time that teachers and students live together in a physical space to realize face-to-face communication and interaction. However, due to the long-term teaching concept, teaching environment and teaching methods in China, the traditional classroom is mainly instilled by teachers, forming the reality that students are not active in participating in the interaction, and the atmosphere of classroom interaction is insufficient.

Online teaching is not face-to-face. Although there are inherent deficiencies in communication and interaction, online interaction has acquired advantages beyond face-to-face interaction due to the extensive innovation and application of modern information technology-modern information technology provides comprehensive technical support for us to conduct in-depth interaction in teaching. Students can overcome the psychological barriers of face-to-face interaction, actively participate in online teaching interaction, so as to form a deep interactive online teaching process, make full use of independent, collaborative and inquisitive learning methods, adhere to the development and cultivation of students' quality in all aspects, to achieve our educational goal of teaching and 
educating people.

\subsection{Research Status and Problems}

The teaching process is not only classroom teaching, but also should include the teaching outside the classroom, especially the university teaching, which pays more attention to the cultivation of students' learning ability.

\subsubsection{Research on Interaction and Classroom Teaching Interaction}

The word "interaction" comes from the research field of social philosophy and refers to "the interaction between people in society" (GH. Mead, 1913). It is a process in which two or more people interact with each other in views, thoughts and feelings and interact or influence each other (Brown, 2001) [1]. It exists between people. Between things or between people and things (environment) (Zuo Bin, 2002) [2].

Classroom is an organic "ecosystem" with continuous interaction between students, teachers, teaching content, technology and physical environment (Yang Qing Yu, 2008). Classroom teaching interaction is a special interaction in the special environment of the classroom. It is a series of interactive activities between teachers and students, students and students, and teachers and students and technology, which revolve around the educational and teaching objectives and mobilize all elements to participate in classroom teaching activities. This is a continuous ecological process of overall dynamic generation (Zhong Qi Quan, 2010) [3].

\subsubsection{Research on Types of Teaching Interaction}

Based on different perspectives, the classification criteria of teaching interaction are different, so the classification research has its own characteristics. For quite a period of time, the research on the classification of teaching interaction has focused on the subject of classroom teaching, that is, between teachers and students, which is determined by the traditional classroom form. There important Kang-Ning Wu et al. (1999) [4] to participate in classroom interaction of the main body is divided into three kinds of individual teachers, students and student's groups, individual teacher and the student individual, group, individual teacher and student individual students and students, students individual and group, student group of five types of classroom interaction and student's groups (Zhou Huiying, 2019) [5].

With the development of information technology, technology has gradually become an important part of classroom teaching. The interaction of classroom teaching with information technology is more complicated. The teaching interaction with the participation of information technology is introduced, and the interactive subjects (elements) are divided into six interaction modes among teachers, students, content and technology, that is, teacher-student interaction, student-content interaction, teacher-technology interaction, student-technology interaction and mixed type (Lou Yi Dan, 2019) [6]. 
As can be seen from the above relevant research status, the research on the connotation of teaching interaction is mainly limited to the form and connotation of teaching interaction itself, and few of them reflect the essence behind the teaching interaction behavior - the harvest that students get through the interaction is the effect of teaching interaction; In the research of teaching interaction types, the limitation of traditional classroom connotation is basically not broken away, and there is a lack of in-depth analysis of the interaction in the whole process of teaching.

\subsection{Problems to Be Solved in This Paper}

Teaching process is a process of exchange of emotion and wisdom between teachers and students. Therefore, "teaching interaction" refers to a series of interactive activities in which teachers and students participate in the teaching environment and all elements of the teaching process (including students, teachers, knowledge, teaching technology media, etc.) are carried out to realize the continuous improvement of the cognitive level of teachers and students and the growth of wisdom.

Under the background of the deep integration of information technology and teaching, online teaching gradually expands the connotation of classroom. Teaching is no longer limited to the 45-minute class, but extends to the whole learning process. Meanwhile, teaching interaction also runs through the whole teaching process. The role and significance of out-of-class interaction are also highlighted, which can lead students into the state of deep learning.

This paper will analyze and study the connotation of deep teaching interaction and the characteristics and advantages of deep online teaching interaction from the perspective of considering the essential elements of teaching interaction, sort out the types of deep teaching interaction in the whole process of teaching, and discuss the value embodiment of deep online teaching interaction.

\section{The Basic Connotation of Deep Interaction in Teaching}

Is done through classroom teaching, classroom teaching effect is in the classroom within the individual cognitive needs and self-actualization needs through a variety of interactive and content, the implementation of the interactive teaching, breaks through the traditional classroom to classroom, teaching materials, teachers "as the center, therefore, become the important link of modern classroom teaching, teaching interaction It also directly affects the effective development of classroom teaching and teaching results.

\subsection{Online Interactive Classes}

The traditional classroom is a place (environment) where students are centrally organized to learn. Usually, teachers and students gather in a relatively small physical space that is easy to perceive and communicate with each other.

With the wide and deep application of modern information technology such 
as Internet, Internet of Things, mobile communication technology, intelligent technology and big data in education and teaching, the role and position of modern information technology in education and teaching has been expanded from serving education and teaching to serving teaching and educating people in the whole process of important technical support.

Online interactive classroom is a new type of classroom which is the result of the deep integration of information technology and education. Online interactive classroom is a teacher will new media and new technologies into classroom teaching, online for learners to create situations, intelligent, interactive learning environment, guide students to find problems, thinking and creative problem solving, and finally promote students deep learning, intelligence growth of new classroom (Cui Xiaohui Zhu Xuan, 2017) [7].

From the perspective of education, online interactive classroom allows students to find and solve problems with innovative ways of thinking, and promotes deep learning and intelligent growth of students. From a technical perspective online interactive classroom emphasis on online classroom intelligent perception, modern information technology, mobile intelligent terminal applications, etc., through large data analysis based on dynamic online interactive teaching and cloud technology, to realize teaching interaction, feedback is immediate, digital resources intelligent push, etc., comprehensive innovation form and content of online teaching, Building an informationized online interactive classroom in the era of big data (Sun Shuhui, Liu Bang Qi, 2015) [8].

\subsection{Traditional Teaching Interaction}

Traditional teaching interaction mainly refers to the traditional classroom teaching interaction. The traditional classroom teaching is carried out under the traditional class teaching mode; however, in the traditional classroom teaching, the teaching elements are only teachers and students, textbooks and simple teaching AIDS, and the application of modern information technology is almost absent. Therefore, the traditional teaching interaction is the real time interaction between teachers and students and students in the special environment of classroom. The scope of traditional teaching interaction is defined in classroom teaching, which generally does not include extracurricular interaction.

From the perspective of interaction duration, due to the lack of the application of modern information technology, the process and content of traditional teaching interaction are not easy to be preserved, so it can only be based on real-time interaction, supplemented by delayed interaction (such as homework, etc.). Therefore, teaching interaction is generally understood to refer to real-time interaction.

\subsection{In-Depth Interaction of Online Teaching}

After depth interaction refers to the students in the interactive learning can take the corresponding knowledge into their original cognitive structure, to question 
and make bold assumptions, finally verify the hypothesis, the process of learning to understand the knowledge to become and be able to migrate to other situations and applications, solve new problems, to achieve deep learning (JiPing, 2018) [9]. However, the intervention of modern information technology, network technology, online education technology and intelligent technology equipment in the teaching process has greatly improved the depth of teaching interaction.

Online interactive classroom increased compared with the traditional classroom information technology is an important element, online interactive classroom based on information technology can create interpersonal, people skills, entry and so on multi-dimensional three-dimensional interactive learning scene, make individuals and between individuals, between group and group, individual and group interaction become the most important core online interactive classroom interaction forces. At the same time, due to the participation of information technology means, the interactive process and the interactive content have been digitized, so that the interactive content and the interactive process have been saved, and the interaction is no longer limited to real-time interaction, and the delayed interaction in and out of class has also become an important content.

From the perspective of the teaching process, the interaction of online interactive classroom includes pre-class instruction-teachers prepare for teaching and students prepare for learning; Interaction in class-show communication, full attention; After-class expansion-multi-point linkage, personality interaction, etc. Online teaching interaction covers the whole process of teaching, and delayed interaction is also fully applied to increase the means and content of interaction, so that students can interact on the basis of deep thinking to achieve deep learning. The quality of interaction is significantly improved, which can be understood as deep teaching interaction.

\subsection{Advantages of In-Depth Interaction in Online Teaching}

In the interactive environment of online interactive classroom, a variety of energy such as knowledge, information and emotion are transmitted, collided and generated mutually. In this process, methods, skills, personal qualities and values have been gradually deposited, internalized and improved.

From the technical point of view, the online interactive classroom relies on data mining technology to analyze the massive teaching data and realize the tracking and analysis of the whole process of learning with big data. It has the characteristics of intelligence in learning and analysis. Online interactive classroom can make full use of the results of data analysis and perceive the learning situation, and push personalized learning content in real time according to the learning needs. In terms of content presentation, it has the feature of real-time push. Using Internet and other technologies, online interactive classroom can realize hierarchical, classified and networked storage of resources. Teachers and students can upload or download all kinds of resources, which can effectively 
realize resource sharing.

Therefore, online interactive classroom is characterized by hierarchical sharing of resources. Online interactive classroom can realize visual feedback and immediate evaluation between teachers and students, so that teachers can know students' learning situation in time, and guide and adjust the teaching content in a targeted way.

In-depth interaction of online teaching innovates the content and form of teaching interaction, breaks through the limitations of traditional teaching interaction, and forms an in-depth teaching interaction featuring diversified interactive forms, in-depth interactive content, digitalized interactive process, and data-oriented interactive evaluation.

\section{The Types of Deep Interaction in Teaching}

Under the background of the deep integration of information technology and teaching, the interaction of online interactive classroom teaching is more rich and diverse. Compared with the general teaching interaction, the in-depth interaction of online teaching includes two innovations: the deepening and expansion of the form and content of interaction and the extension of the classroom process. First of all, information technology and students and teachers will produce rich interaction, classroom teaching interaction is not only the original single interpersonal interaction, but also includes teachers and students and information technology interaction, classroom teaching interaction also has a new connotation. Secondly, due to the deep application of information technology, teaching interaction is not only real-time, but also can be delayed interaction. This enables us to extend the teaching process and teaching interaction of online class. Online interactive class is no longer the "45-minute class" of traditional teaching, but extends the teaching interaction to the whole "learning process". Different from the immediacy of traditional classroom interaction, online teaching gives full play to the immediacy and delay of interaction.

Based on the above analysis, according to the students, teachers, knowledge content and technical environment of the four elements of classroom interaction, and considering the delay of online teaching interaction, combined with specific online teaching practice, we divide the in-depth online teaching interaction into four types: interpersonal real-time interaction, interpersonal delay interaction, interpersonal knowledge interaction and human-technology interaction.

\subsection{Real-Time Human Interaction}

Real-time interpersonal interaction refers to the real-time communication and interaction between students and teachers using real-time communication tools, including the real-time communication and interaction in online class and after-class, such as the selection of students, class, instant questionnaire survey, check-in, etc., as well as the real-time chat in real-time chat tools, etc. This in- 
cludes single interaction between teachers and students, group interaction between teachers and students, single interaction between students and students, group interaction between students and students, etc.

The real-time interpersonal interaction is realized in the real-time teaching process. Mainly in the teaching of real-time communication and discussion, timely communication, feedback at any time, rapid reflection. As well as classroom live teaching, teaching video (barrage technology) application. In the form of real-time situational interactive questions, such as question discussion, sign-in, selection, questionnaire survey and emotional communication, it is used in the interactive part of class.

\subsection{Lengthening Interpersonal Interaction}

Interpersonal delayed interaction refers to that the interactive information is first stored through information exchange tools, and then the other party responds to the feedback after consulting the information, considering and convenient, so as to realize non-immediate online communication and interaction. Mainly is the problem discussion, the academic exchange, the course assignment, the interactive message and so on, including the teacher-student interaction, the student interaction, can solve the teacher-student, the student time conflict, is convenient to find the problem at any time, the exchange interaction at any time.

Interpersonal delay interaction is realized and completed in the learning process before and after class. The interactive forms of preset situational questions such as questions, discussions and assignments are used in the pre-class learning section (teachers prepare for teaching and students prepare for learning) and after-class extended learning.

\subsection{People Know Interaction}

Human interaction refers to the interaction between human and the teaching content and knowledge. It is the teacher's grasp of the teaching content and knowledge, design the teaching plan, discuss the problems and homework to guide the students to learn. The process in which students consult materials, learn to master and understand knowledge includes interaction between students and content and interaction between teachers and content.

Student-content interaction refers to students preview, think about the learning content, collect and expand the learning materials, understand and absorb the knowledge content, put forward questions and inspirations, and share the materials. The teacher-content interaction refers to that the teacher organizes the teaching content according to the teaching requirements, puts forward thinking content problems, learning methods, skills, ideas and so on to guide the students to learn and grasp the relevant knowledge content.

\subsection{People and Technology Interaction}

Human technology interaction refers to the interaction between human and the 
technological environment, the mastery and application of information technology and information system, and the support and guarantee of human interaction and human knowledge interaction. Including teachers and students, namely the interaction between teachers and technological environment and the interaction between students and technological environment.

The online interactive teaching platform uses information technology and data mining methods to record, collect and integrate the online interaction and learning behavior data of students and teachers, and store them classified. Using technology to assist teaching, teachers can grasp the learning and interaction of students at any time, give immediate feedback, grasp the teaching pertinence, control and improve the teaching effect; Students use technology to study independently and collaboratively, grasp their own learning status at any time, adjust their learning content and ideas, and successfully complete their learning tasks.

Students can interact with each other through mobile phones, tablets, computers and other terminals, including: sign-in, answering in advance, content issued by teachers, content uploaded by students, achievement display, rewards, and mutual evaluation by students. These simple interactions are also human-skill interactions.

\section{The Value of Deep Interaction in Teaching}

Online interactive teaching, information technology for learning space, changes of innovative learning methods and learning environment, as well as to the study of information gathering and the change of the push mechanism, makes the knowledge learning and build more and more inseparable from the mutual communication, learning is no longer an individual to act alone, but a group of interconnected to build process. Therefore, the value of teaching depth interaction is mainly reflected in the following aspects.

\subsection{Induce Deep Learning}

Deep learning is learning in a state of high motivation, which involves the whole process of knowledge collection, processing and construction.

Online interactive classroom fully relies on students, mobilizes students' emotional state, participation state and thinking state, and transforms from single teaching interaction to deep teaching interaction.

Interactive online learning requires active preparation. It is different from the traditional classroom in which teachers lead students to "review the old knowledge, explain the new knowledge, consolidate knowledge, practice feedback" process. On the premise of students' active learning, on the basis of students' active participation, willing to explore and diligent in doing, existing experience and knowledge system are used to deeply understand knowledge, take the initiative to interpret information and knowledge, and construct new knowledge, which can be brought into the interactive links in class, so as to trigger deep learning. It no longer regards knowledge and skills as solidified things for people 
to grasp and store, but promotes students to construct a knowledge network system by themselves, and experiences the learning transition from passive to active, from simple to rich, from mechanical to flexible, and from closed to open.

\subsection{Build a New Type of Teacher-Student Relationship}

The present teacher-student relationship in China is characterized by democracy, equality and mutual assistance. In the modern student-centered teacher-student relationship, it is no longer a single mode of knowledge instilling by teachers in traditional education, but a complex process of knowledge exploration and knowledge construction that is advocated by students under the guidance of teachers. Online interactive classroom is dominated by students' active learning so as to construct the teacher-student relationship of new knowledge impartation.

Online interactive classroom takes students as the main body to form "learner input", which is a state of "high attention and participation of learners". Participation is not only at the cognitive level, but also at the social, behavioural and emotional levels.

Online interactive classroom, the students' knowledge by teachers to instill and no longer, but take the student as the main body, give full play to students' subjective initiative, through training the students' thinking ability, causes the student to carry out the knowledge of the exploratory study, dominated by teachers at the same time, on the one hand, to cultivate the students' ability and autonomous learning ability, On the one hand, when students have knowledge confusion, they can be guided to solve the confusion, so that students can make correct knowledge judgment and finally spontaneously construct knowledge.

\subsection{Adapt to the Interactive Characteristics of College Students in the New Era}

Students in the new era are characterized by extensive and in-depth use of modern information technology and intelligent facilities for communication. Good at using the information network to carry out online communication, such as text, graphics, facial expressions and voice. Online interaction conforms to the trend of the Internet age and overcomes the lack of students who are not good at talking.

\subsection{Comprehensive Development of Students' Information Quality}

Online interaction in the classroom, with students as the main body, students from gathering information knowledge, analysis the information share information, exchange knowledge to understand the knowledge of building content, in the process of the active learning allows students to collect and process information ability, the ability of acquiring new knowledge, analysis and problem-solving skills and be fully improve the communication and cooperation ability. 


\section{Conflicts of Interest}

The authors declare no conflicts of interest regarding the publication of this paper.

\section{Fund Projects}

1) Major Online Teaching Reform Research Project of Anhui Province "Research on the Enhancement of Online Teaching Depth Interaction" (2020ZDXSJG001).

2) Anhui Province "Six Excellence One Top" Outstanding Talents Training Innovation Project "E-commerce Professional Excellent E-commerce Division Training Innovation Project” (2020ZYRC004).

3) The First-class Major Construction Project of Anhui University of Finance and Economics (E-Commerce) (Acylzy2020004).

\section{References}

[1] Brown, H. (2001) Teaching by Principles: An Interactive Approach to Language, Pedagogy. Foreign Language Teaching and Research Press, Beijing, 156.

[2] Zuo, B. (2002) Teacher-Student Interaction Theory-A Psychological Study of Classroom Teacher-Student Interaction. Central China Normal University Press, Wuhan, 73-77.

[3] Zhong, Q.Q. (2010) The Study of Classroom Interaction and Its Implications. Educational Research, 369, 73-80.

[4] Wu, K.N., et al. (1999) Sociology of Classroom Instruction. Nanjing Normal University Press, Nanjing.

[5] Zhou, W.Y. (2019) Research on Teaching Interaction Model in Smart Classroom Environment. Software Guide, 18, 18-21.

[6] Lou, Y.D. (2019) Research on Effective Teaching Interactive Strategies in Intelligent Learning Environment. Master Dissertation of Zhejiang Normal University, Zhejiang.

[7] Cui, X.H. and Zhu, X. (2017) Characteristics and Practice of Intelligent Classroom Teaching Model. Vocational Education Communication, 21, 69-72.

[8] Sun, S.H., Liu, B.Q. (2015) Intelligent Classroom Model Based on Dynamic Learning Data Analysis. China Educational Informatization, 22, 21-24.

[9] Ji, P. (2018) A Study on the Debate Strategy for Promoting Students' Deep Interaction. Master Dissertation of Nanjing Normal University, Nanjing, 4. 